\title{
Unprotected sex among men who have sex with men living with HIV in Brazil: a cross-sectional study in Rio de Janeiro
}

Cynthia Braga Cunha, Raquel Brandini De Boni", Maria Regina Cotrim Guimarães, Carolyn Yanavich, Valdilea Gonçalves Veloso, Ronaldo Ismerio Moreira, Brenda Hoagland, Beatriz Grinsztejn and Ruth Khalili Friedman

\begin{abstract}
Background: Many countries are facing concentrated HIV epidemics among vulnerable populations, including men who have sex with men (MSM). Unprotected anal intercourse (UAI) is the main HIV transmission route among them and its understanding in the different cultures and how it relates to HIV transmission, re-infection and development of HIV antiretroviral resistance has important public health implications. Data on UAI among Brazilian MSM are scarce. This study aims to evaluate the prevalence and associated factors of UAl among HIV-infected MSM who had sex with seronegative or male partners with an unknown serostatus.
\end{abstract}

Method: A cross-sectional study nested in a cohort was conducted in Rio de Janeiro, Brazil. The one hundred and fifty five MSM included in the study answered an ACASI interview and provided biological samples. Generalized linear models were used to identify variables associated with UAl.

Results: Overall, UAI with an HIV-negative or unknown serostatus male partner was reported by $40.6 \%$ (63/155) of MSM. Lifetime sexual abuse or domestic violence was reported by $35.9 \%$, being more frequent among MSM who reported UAl compared to those who did not $(P=0.001)$. Use of stimulants before sex was reported by $20 \%$ of the MSM, being slightly higher among those who reported UAI (27.0\% vs. 15.2\%; $P=0.072)$. Commercial sex was frequent among all MSM (48.4\%). After multivariate modeling, the report of sexual abuse or domestic violence $(\mathrm{OR}=2.70 ; 95 \% \mathrm{Cl}$ : 1.08-7.01), commercial sex $(O R=2.28 ; 95 \% \mathrm{Cl}: 1.04-5.10)$, the number of male sexual partners $(p=0.039)$ and exclusively receptive anal intercourse (OR $=0.21 ; 95 \% \mathrm{Cl}: 0.06-0.75)$ remained associated with UAI. CD4 levels, HIV viral load and antiretroviral therapy were not associated with UAI.

Conclusion: The UAI prevalence found with negative or unknown HIV status partners points out that other interventions are needed as additional prevention tools to vulnerable MSM. The main factors associated with UAI were a lifetime history of violence, commercial sex and the number of male sexual partners. This clustering of different behavioral, health and social problems in this population reinforce the need of a comprehensive approach on treating and preventing HIV among MSM.

Keywords: Men who have sex with men, HIV/AIDS, Unprotected anal intercourse, Low and middle income countries

\footnotetext{
*Correspondence: raqueldeboni@gmail.com

Laboratório de Pesquisa Clinica em DST/AIDS, Fundação Oswaldo Cruz - Instituto de Pesquisa Clínica Evandro Chagas/IPEC, Avenue Brasil, 4365 - Manguinhos, Rio de Janeiro RJ CEP 21040-900, Brasil
}

\section{Biomed Central}

(c) 2014 Cunha et al.; licensee BioMed Central Ltd. This is an Open Access article distributed under the terms of the Creative Commons Attribution License (http://creativecommons.org/licenses/by/2.0), which permits unrestricted use, distribution, and reproduction in any medium, provided the original work is properly credited. The Creative Commons Public Domain Dedication waiver (http://creativecommons.org/publicdomain/zero/1.0/) applies to the data made available in this article, unless otherwise stated. 


\section{Background}

Men who have sex with men (MSM) remain a vulnerable population for HIV infection across the world [1]. In Brazil, HIV prevalence among the general population is below $0.6 \%$ [2]. However, in the largest study conducted in the country, HIV prevalence among MSM ranged from $9.1 \%$ to $16 \%$ [3]. Soon after the onset of the HIV epidemic, there were reductions in transmission among MSM due to the expansion of condom use [4] or even sexual abstinence [5,6]. Although condoms represent an effective barrier against sexual transmission, since the mid-1990s the proportion of men reporting unsafe sex - including "barebacking", i.e. unprotected anal intercourse (UAI) in a risk context [7] - seems to have increased [8-11].

UAI is the main HIV transmission route among MSM [12]. Studies designed to increase the understanding about this sexual practice in the different cultures and how it relates to HIV transmission, re-infection and development of HIV antiretroviral resistance may have important public health implications. A meta-analysis from studies conducted in the US estimated an overall UAI prevalence among HIV-infected MSM at 43\% (CI 95\% 3748) [12], with lower frequencies when sexual partners were of unknown $(30 \%)$ or negative $(16 \%)$ serostatus [12]. These differences may be related to the "sexual harm-reduction" approaches, such as serosorting (the use of the partners' HIV serostatus - actual or presumed - as a guidance to make decisions when having UAI), strategic positioning (selectively engage in receptive UAI rather than insertive UAI) and negotiated safety (as agreements between steady couples related to sex with casual partners) [13-16].

Data on UAI prevalence and associated factors among Brazilian MSM are scarce, which limits the effectiveness of public policies designed to decrease HIV infection in this population. In a study conducted with over 3,000 HIV-positive and negative Brazilian MSM, UAI prevalence was $36.5 \%$, and the associated factors reported were in accordance with the international literature [17]. However, the authors did not disaggregate data according to HIV serostatus, precluding inferences about attitudes and behaviors associated to HIV transmission.

Behavioral and contextual factors, specifically a higher number of sexual partners [18-20], a history of domestic or sexual violence [21,22], alcohol and illicit drug use, particularly stimulants [23-27], have been associated with UAI among MSM in the international literature. Given the importance of combined anti-retroviral therapy (cART) in the treatment and prevention of HIV infection [28], researchers have also investigated the potential impact of its use, and consequential undetectable viral loads, on UAI reporting. Even though some results showed an increase in UAI among individuals with known undetectable viral load (UVL) [29] or with the belief that UVL decreases transmission [30], most evidence suggest that there is no association between UAI and UVL/ cART use [31-34].

Considering the sustained high incidence rate of HIV among MSM and the lack of information on UAI among HIV-infected South American MSM, this paper aims to study the prevalence and associated factors of UAI among HIV-infected MSM in Brazil.

\section{Methods}

A cross-sectional analysis, nested within a cohort study was conducted at Instituto de Pesquisa Clinica Evandro Chagas (IPEC/FIOCRUZ), Rio de Janeiro, Brazil. A convenience sample of HIV-infected and non-infected high risk MSM older than 18 years was enrolled since 2010. Briefly, the cohort was designed to evaluate the prevalence and incidence of anal HPV infection and intraepithelial anal lesions. Participants were considered to be MSM if they had a male sexual partner (s) in the past 12 months, regardless of having a female partner (s).

\section{Participants}

The study population for the present analysis was a subset of HIV-infected MSM enrolled in the parent cohort, who reported having had anal intercourse with men at risk for HIV infection (HIV negative or with an unknown HIV serostatus) within the past 3 months.

Two hundred ninety four HIV-infected MSM were enrolled into the IPEC/FIOCRUZ men's cohort from August 2, 2010 to June 30, 2012. Of these 294 MSM, a total 190 MSM were excluded from this analysis for the following reasons: $85 / 294$ (28.9\%) reported no male sexual partner/no anal intercourse in the past 3 months; 34/ 294 (11.6\%) reported anal intercourse exclusively with an HIV-infected male partner; and 20/294 (6.8\%) had missing data for anal intercourse data (Figure 1). Final sample was comprised by 155 HIV-infected MSM.

\section{Measures}

The outcome was defined as UAI with at least one man of unknown or negative HIV status in the 3 months preceding the interview.

Demographic variables were collected at enrollment visit and included: age, self-reported skin color (white and nonwhite) and schooling (years of formal education).

Data on behavior variables were collected during the enrollment visit via Audio Computer Assisted Interview (ACASI), which included the following:

- Number of male partners within the last 12 months ("During the past 12 months, how many men and how many transvestite/transsexual/transgender (s) did you have sex with?"); 


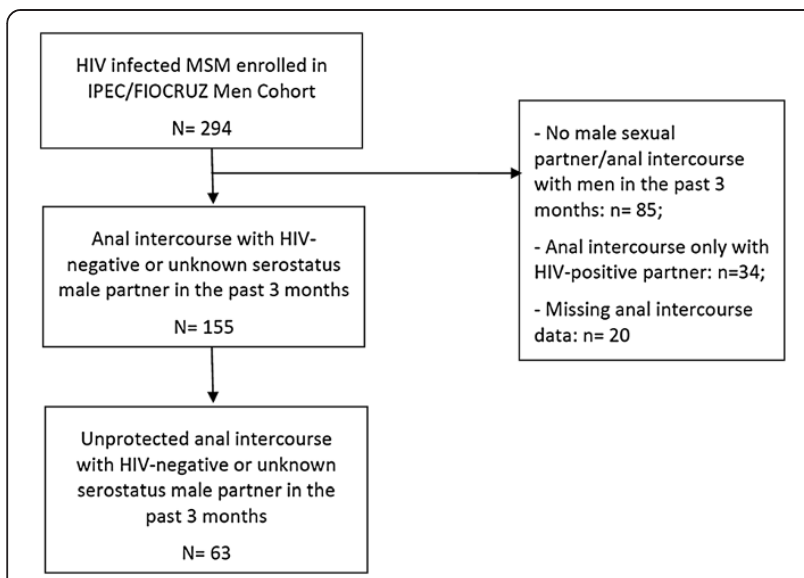

Figure 1 Study population and outcome, IPEC/Fiocruz, 2010-2012.

- Anal intercourse practices in the past 3 months was measured through the following questions: a-"In the past 3 months, how many HIV-negative male partners did you have insertive anal sex with?"; b- "In the past 3 months, how many male partners, with an unknown HIV-serostatus, did you have insertive anal sex with?"; c- "In the past 3 months, how many HIV-negative male partners did you have receptive anal sex with?"; d-“In the past 3 months, how many male partners, with an unknown HIV-serostatus, did you have receptive anal sex with?". The questions above were used to select the study population and were also used to formulate the variable "Anal intercourse practices" and its subcategories of "only insertive", "only receptive" or "both".

- Unprotected anal intercourse in the past 3 months was measured by the following questions: a- "In the past 3 months, how many HIV-negative male partners did you have insertive anal sex with, without using condoms?"; b- "In the past 3 months, how many HIV-unknown male partners did you have insertive anal sex with, without using condoms?"; c- "In the past 3 months, how many HIV-negative male partners did you have receptive anal sex with, without using condoms?"; d- "In the past 3 months, how many male partners, with an unknown HIVserostatus, did you have receptive anal sex with, without using condoms?".

- Alcohol use, either before or during sex, within the past 3 months was measured by the question "In the past 3 months, were you drunk or high before or during sex?");

- Stimulant use, either before or during sex, within the past 3 months was measured by the question "In the past 3 months, did you use either inhaled or intravenous illicit drugs before or during sex?"; Lifetime injection drug use was measured by the question "Have you ever used intravenous illicit drugs in your life?"; however, due to limited observations, this response was not evaluated in the models.

- Commercial sex within the past 3 months was defined as the exchange of sex for money/other favors and/or the looking for prostitutes: "In the past 3 months, did you have sex for money, drugs or other favors?" and "In the past 3 months, did you look for prostitutes?".

- A lifetime history of sexual abuse or violence was determined based on a composite measure of the responses to the following 2 questions: "Did you ever suffer domestic violence in your life?" and "Did you ever suffer sexual abuse in your life?");

- The Clinical and laboratory variables included the following:

- Time since HIV diagnosis was defined as the time since the first HIV-positive serology result until the date of the interview; results were presented using the median (interquartile range).

- Combined antiretroviral therapy (cART) was defined as the date of issuance of the initial prescription for combined antiretroviral treatment until the date of the interview. Individuals who have a cART prescription were classified as receiving CART.

- CD4 $4^{+}$T cell count (cells $/ \mathrm{mm}^{3}$ ) was defined as the available result closest to the date of the interview. The specimens to measure $\mathrm{CD} 4^{+} \mathrm{T}$ cell count were obtained within a window period of 6 months before and up to 3 months the interview. Data was presented as median and interquartile range.

- HIV viral load (copies/IU). Specimens were collected on the day of the interview and results were classified as either undetectable (less than 400 copies/IU) or detectable (equal to/higher than 400 copies/IU).

All biological analyses were performed at the IPEC Laboratories, which successfully participates in the College of American Pathologists (CAP) External Quality Assurance (EQA) proficiency testing panels and is certified by the Division of AIDS' Virology Quality Assurance (VQA) program for quantitative and qualitative HIV assays.

\section{Statistical analysis}

Descriptive analysis and proportions of men who reported UAI in the past 3 months were presented. Chi-square tests and Fisher exact tests were used for categorical variables, and Student $t$ test were used for continuous variables. Generalized linear models with logit link and binomial distribution [35] were used to identify independent variables associated with UAI in the past 3 months in the study population. Age (years) and the number of 
male partners in the last 12 months were modeled as restricted cubic splines with three knots [36].

After univariate analysis, observations with missing information on any selected variable were excluded. Covariates with $\mathrm{p}$ values $<0.10$ were selected, assessed for multi-colinearity using generalized colinearity diagnostics (GVIF) and entered in the initial multivariate model. Based on prior information concerning the effect of age in HIV incidence [37], we forced a priori the variable age as a continuous variable into the multivariate models. Covariates with the highest $\mathrm{p}$ values in the analysis of deviance (analogous to the likelihood ratio test) were sequentially removed. Variables with statistical significance at $5 \%(\mathrm{p}<0.05)$ and those that were not considered a confounder (e.g., when removed, a change equal to or higher than $10 \%$ in the odds ratio of any other variable of the model was observed) remained in the final model [38]. The Akaike Information Criterion (AIC) was also used for model selection. The Le Cessie-van Houwelingen-Copas-Hosmer test was used to evaluate the goodness-of-fit of the final model [39]. The predictive ability was evaluated using the Area Under the ROC Curve (AUC). Overdispersion was verified as well as the analysis of the residuals (Pearson and deviance residuals and Leverage or Cook's distances). The software R 3.0.2 was used to generate all analyses [40].

\section{Ethics}

The study was approved by the IPEC-FIOCRUZ IRB (CAE 0044.0.009.000-09) and all study participants signed an informed consent form prior to enrollment into the cohort.

\section{Results}

One hundred and fifty five MSM who reported anal sex with either an HIV-negative partner or a male partner with an unknown HIV-serostatus within the past 3 months were included. Overall, UAI with an HIV-negative or unknown HIV-serostatus male partner was reported by 40.6\% (63/155) of MSM: 7.9\% were exclusively with an HIV-negative partner, $76.2 \%$ were exclusively with a partner with unknown HIV-serostatus and $15.9 \%$ with both, as shown in Table 1.

Table 2 describes the sociodemographic, behavioral, clinical and laboratorial characteristics of the study participants by UAI. Median age was 38 years, $53.6 \%$ were self-identified as white and $84.2 \%$ had more than 8 years of formal education. No significant differences at $\mathrm{p}<0.10$ level were observed in chance of UAI and skin color $(P=0.799)$ and years of education $(P=0.882)$. The median number of male sexual partners in the 12 months prior to the interview was 6.0; it was higher among those who reported UAI (Median $=10 ; \boldsymbol{P}=\mathbf{0 . 0 3 8}$ ). Having only a single partner during the 12 months prior to the interview was reported by $12.4 \%$.

Lifetime sexual abuse or domestic violence was reported by $35.9 \%$ and was significantly greater among MSM who reported UAI compared to those who did not $(p=0.001)$. Although $36.8 \%$ of MSM reported to be "high" from alcohol use before/during sex in the past 3 months, this was not statistically different from those who reported UAI and those who did not report UAI $(P=0.337)$. Stimulant usage before/during sex in the past 3 months was reported by $20.0 \%$ of the MSM, being slightly higher among those who reported UAI when compared to the group who did not. $(27.0 \%$ vs. $15.2 \%$; $P=0.072$ ). Only 4 study participants (2.6\%) reported injecting drug use during their lifetime.

Commercial sex in the past 3 months was frequent among all MSM (48.4\%) and positively associated with UAI $(\boldsymbol{P}=\mathbf{0 . 0 0 1}) .58 .1 \%$ participants reported both insertive and receptive sexual practices, while an exclusively insertive sexual practice was reported only by $16.1 \%$. UAI was less frequently reported in exclusively receptive MSM (11.1\%) when compared to those with exclusively insertive $(17.5 \%)$ or with both insertive and receptive sexual practices $(71.4 \%) .(\boldsymbol{P}=\mathbf{0 . 0 0 2})$.

The median time since HIV diagnosis was 72.0 months and this was not associated with UAI $(P=0.866)$. Almost $82 \%$ of MSM were receiving cART at the time of the interview; this was associated with a lower likelihood of UAI $(\boldsymbol{P}=\mathbf{0 . 0 4 4})$. Median CD4 count was higher among MSM who had UAI compared to those who did not report UAI, although no significance was observed at $10 \%$ $(P=0.116)$. Roughly half of the participants had an undetectable HIV viral load; this was not associated to a higher likelihood of having UAI $(P=0.846)$.

Multi-colinearity was not observed among significant variables $(\mathrm{P}<0.10)$ and age after univariate analysis, which

Table 1 Unprotected anal intercourse according to partner (s) HIV-serostatus, IPEC/FIOCRUZ, 2010-2012

\begin{tabular}{|c|c|c|c|c|c|c|}
\hline \multirow{3}{*}{$\begin{array}{l}\text { HIV partner } \\
\text { serostatus }\end{array}$} & \multicolumn{6}{|c|}{ Unprotected anal intercourse within the past 3 months } \\
\hline & \multicolumn{2}{|c|}{ No } & \multicolumn{2}{|c|}{ Yes } & \multicolumn{2}{|c|}{ Total } \\
\hline & $\mathbf{N}$ & $\%$ & $\mathbf{N}$ & $\%$ & $\mathbf{N}$ & $\%$ \\
\hline Only HIV-negative & 23 & 25.0 & 5 & 7.9 & 28 & 18.1 \\
\hline Only unknown HIV & 57 & 62.0 & 48 & 76.2 & 105 & 67.7 \\
\hline Both & 12 & 13.0 & 10 & 15.9 & 22 & 14.2 \\
\hline Total & 92 & 100.0 & 63 & 100.0 & 155 & 100.0 \\
\hline
\end{tabular}


Table 2 Characteristics of UAI with an HIV negative/unknown serostatus partner within last 3 months ( $N=155)$, IPEC/FIOCRUZ, 2010-2012

\begin{tabular}{|c|c|c|c|c|}
\hline \multirow[t]{2}{*}{ Characteristics } & \multicolumn{3}{|c|}{ Unprotected anal intercourse } & \multirow[t]{2}{*}{ P-value* } \\
\hline & $\begin{array}{c}\text { No } \\
92(\%)\end{array}$ & $\begin{array}{c}\text { Yes } \\
63(\%)\end{array}$ & $\begin{array}{l}\text { Total*** } \\
155(\%)\end{array}$ & \\
\hline $\operatorname{Age}^{* *}$ & $40.5(31.5-48.0)$ & $37.0(32.0-43.0)$ & $38(32.0-45.0)$ & 0.107 \\
\hline White & $48(52.7)$ & $34(54.8)$ & $82(53.6)$ & 0.799 \\
\hline Years of education & & & & 0.882 \\
\hline$<4$ & $5(5.6)$ & $2(3.2)$ & $7(4.6)$ & \\
\hline 4 a 8 & $10(11.1)$ & $7(11.3)$ & $17(11.2)$ & \\
\hline$>8$ & $75(83.3)$ & $53(85.5)$ & $128(84.2)$ & \\
\hline No of male partners last 12 months** & $5.0(2.0-10.0)$ & $10.0(3.0-30.0)$ & $6.0(3.0-15.0)$ & 0.038 \\
\hline Lifetime sexual abuse or violence & $23(25.0)$ & $32(52.5)$ & $55(35,9)$ & 0.001 \\
\hline Alcohol use before sex last 3 months & $31(33.7)$ & $26(41.3)$ & $57(36,8)$ & 0.337 \\
\hline Stimulant use before sex last 3 months & $14(15.2)$ & $17(27.0)$ & $31(20.0)$ & 0.072 \\
\hline Commercial sex last 3 months & $34(37.0)$ & $41(65.1)$ & $75(48.4)$ & 0.001 \\
\hline Anal intercourse with men last 3 months & & & & 0.002 \\
\hline Only insertive & $14(15.2)$ & $11(17.5)$ & $25(16.1)$ & \\
\hline Only receptive & $33(35.9)$ & $7(11.1)$ & $40(25.8)$ & \\
\hline Both & $45(48.9)$ & $45(71.4)$ & $90(58,1)$ & \\
\hline Months since HIV diagnosis** & $70.7(33.3-162.4)$ & $75.0(44.1-134.5)$ & $72.0(33.8-148.8)$ & 0.866 \\
\hline Receiving CART & $80(87.0)$ & $46(74.2)$ & $126(81.8)$ & 0.044 \\
\hline CD4 count $\left(\text { cels } / \mathrm{mm}^{3}\right)^{* *}$ & $541.5(381.0-759.0)$ & $647.0(414.0-927.0)$ & $581.0(393.0-837.0)$ & 0.116 \\
\hline Undetectable viral load & $47(51.6)$ & $28(50.0)$ & $75(51.0)$ & 0.846 \\
\hline
\end{tabular}

were entered in the initial multivariate model. In the final multivariate model (Table 3 and Figure 2), reporting sexual abuse or domestic violence $(\mathrm{OR}=2.70 ; 95 \% \mathrm{CI}: 1.08-7.01)$ and having commercial sex within the past 3 months $(\mathrm{OR}=2.28$; $95 \% \mathrm{CI}: 1.04-5.10)$ were positively associated with UAI, whereas the practice of exclusively receptive anal intercourse $(\mathrm{OR}=0.21$; 95\% CI: 0.06-0.75) was negatively associated with UAI. The shape of the association between the number of male partners in the past 12 months and UAI (modeled as the restricted cubic spline with 3 knots: 1.0, 6.0, 35.0) showed that the chance of UAI for each additional male partner increased quickly among participants who reported up to 20 partners and slowly among those who reported more than 20 ( $p$-value $=0.039$ ). Stimulants use before or during sex and receiving cART remained as confounder variables in the final multivariate model. Despite not having a statistically significant impact on UAI, the shape of association for age (years modeled as the restricted cubic spline with 3 knots: 26.1, 38.5, 51.0) is rather flat, though there is a low chance of UAI at the age extremes $(\mathrm{p}$-value $=0.301)$. There was no overdispersion in the model and the goodness-of-fit as well as the residual analysis were satisfactory.

\section{Discussion}

Most HIV -infected from our study have reported that they did not know their partner's serostatus, which is in accordance with prior data from Latin America [41]. The frequency of UAI with either negative or unknown HIV status partners was higher (40\%) than that described in a metaanalysis conducted with HIV positive MSM from the U.S. (26\%) [12]. Therefore, the risk of transmission, as well as re-infection and other sexually transmitted disease (STD) acquisition is increased among this population. Brazilian efforts on prevention, especially promoting condoms use and providing freely cART, have been very efficient in the control of HIV epidemics among general population [2]. However, they were not enough to control HIV transmission among MSM, a population presenting $10.5 \%$ HIV point prevalence [42]. Thus, the UAI prevalence data presented in this study indicate that other effective interventions, such as Post-exposure prophylaxis (PEP) and pre-exposure 
Table 3 Factors associated with unprotected anal intercourse among MSM who have sex with an HIV negative/unknown serostatus partner within the last 3 months (N=152)*, IPEC/Fiocruz, 2010-2012*****

\begin{tabular}{lcc}
\hline \multicolumn{1}{c}{ Characteristics*** } & $\begin{array}{c}\text { Adjusted OR } \\
\text { (Cl 95\%) }\end{array}$ & P-value \\
\hline Lifetime sexual abuse or violence & $2.70(1.08-7.01)$ & 0.034 \\
Stimulant use before sex last 3 months & $1.48(0.57-3.83)$ & 0.418 \\
Commercial sex last 3 months & $2.28(1.04-5.10)$ & 0.040 \\
Anal intercourse last 3 months & &
\end{tabular}

Anal intercourse last 3 months

\begin{tabular}{rcc} 
Only insertive & 1 & \\
Only receptive & $0.21(0.06-0.75)$ & 0.018 \\
Receptive and insertive & $0.75(0.25-2.22)$ & 0.603 \\
& $0.52(0.18-1.47)$ & 0.218 \\
\hline
\end{tabular}

Receiving CART

$0.52(0.18-1.47) \quad 0.2$

Le Cessie-van Houwelingen-Copas-Hosmer test (P-value): $0.723 ; A U C: 0.795$ data in at least one covariate.

**Age was forced $a$ priori the variable age into the multivariate models; Number of male partners, Stimulant use before sex, and currently receiving CART was a confounder and remained in the final multivariate model. ***Age (years) and Number of male partners within the last 12 months were modeled as restricted cubic spline with three knots (coefficients not shown).

prophylaxis (PrEP) [43-45], are needed as additional prevention tools to vulnerable MSM.

The lifetime history of violence or sexual abuse increased the chances of UAI by almost 3 times. This outcome is particularly concerning seeing that the frequency of UAI for the study population was $40.6 \%$, with greater than half of the men who had UAI reporting previous violence or sexual abuse. Increasing evidence supports the associations of both childhood sexual abuse and intimate partner violence with sexual risk behavior in MSM. An intervention trial [21] aimed to reduce risk behavior in MSM in six American cities found a $39.7 \%$ point prevalence of reported child sexual abuse, which was associated with a 1.24 (95\% CI: 1.12 to 1.36) increased chance of UAI. Similarly, a positive association was found between intimate partner violence and UAI, depression, and substance abuse among 814 MSM from Chicago [46]. Less is known on these issues in middle-income countries [47] and there are still methodological problems to be solved regarding definitions and study design [48], but results found here point to an important and under evaluated threat to health among this population.

Commercial sex within the past 3 months also increased the likelihood of UAI in MSM. In our study, this variable included both MSM who received money in exchange for sex and/or looked for sexual partners on the streets. Because commercial sex is illegal in many countries, accurately assessing frequency of commercial sex is difficult. As a result, the research data on the association of commercial sex with UAI may be underreported and its association with UAI may be therefore difficult to measure. In a sample of MSM who paid for sex in

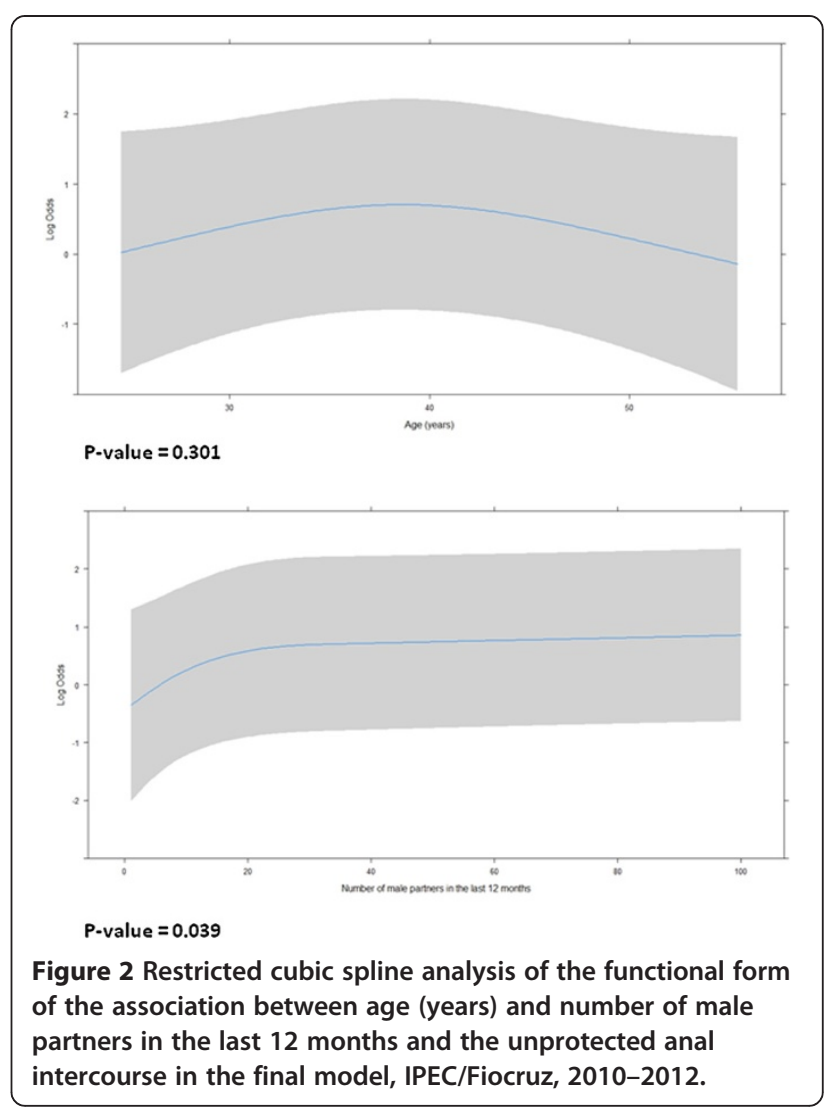

Pakistan, almost $60 \%$ of them reported that their last intercourse event was unprotected [49]; however, more than $80 \%$ of interviewed MSM from India reported to have used condoms during their last paid intercourse with other men [50].

Results are also contradictory on the risk of HIV infection among MSM who exchanged sex for money. A meta-analysis from studies conducted in China found no difference in the HIV infection risk for "money-boys" compared to other MSM [51]. However, in a small recent study, including 463 Chinese MSM from the general population, commercial sex increased the chance of HIV infection by 4 times (95\% 1.19-13.69) [52]. Even less is known about commercial sex among HIV-infected MSM, including possible cultural differences related to stigma and discrimination that may play a factor in the ability to negotiate the use of safe sex practices. As a result, additional research is still necessary on this topic.

Most MSM (57\%) reported both insertive and receptive anal intercourse during the last 3 months, which is in accordance with the international literature [53,54]. MSM who reported having only receptive anal intercourse reported less UAI compared to those who only had insertive sex. These findings may be related to an increased awareness with one's own health and an intention to protect themselves from super-infection and STD. These data also 
raise questions about serosorting and strategic positioning as risk reduction practices among Brazilian MSM. Further studies are necessary to evaluate these practices and risk reduction strategies adopted by HIV-positive MSM and their impact on HIV transmission.

The chance of UAI was associated with the number of male sexual partners within the past 12 months $(\mathrm{P}=0.039)$. However, we could observe that for MSM who had more than 20 male sexual partners, the odds of UAI for each additional partner did not increase as quickly when compared to participants who reported up to 20 partners.

In accordance with the recent literature, viral load and cART use [55,12] were not associated with UAI in this study. In contrast to the available literature, our findings indicated that being a younger age and being "high" from alcohol use or recreational stimulant use before/ during sex were not associated with UAI. However, these findings must be interpreted with caution and the lack of statistical significance may be associated with the small size of our study population. Alcohol and stimulant consumption may be used to increase sexual performance [56], but intoxication decreases risk perception of HIV transmission [57]. Studies conducted with HIVinfected MSM have found a positive association between sexual risk behavior and the excessive consumption of alcoholic beverages [58,30].

Lastly, it is important to highlight that subjects who reported UAI also reported a higher number of sexual partners, a higher frequency of lifetime history of violence, and had a higher frequency of alcohol and stimulant use before/during sex than MSM who had no UAI. Different theories have been proposed to explain the clustering of different health problems/risky behaviors within the same populations. Dr. Merrill Singer, for example, has proposed the concept of syndemics [59], meaning different problems act synergistically in the worsening of health. Several authors have studied the concept of internalized homophobia as a predictor of risky behavior and psychological issues among MSM [60-62]. These theories are far from disentangling the multiple components related to risky behavior, and there is a debate on their real impact on health [63], but they certainly reinforce the need for a comprehensive approach on treating and preventing HIV among MSM.

As our sample is not probabilistic - and results may not be generalized to a broader population - further research is needed. Nevertheless, our results offer insight on factors associated with unprotected sexual practices among HIV-infected MSM in Brazil. As a limitation, the study was not specifically designed to evaluate intimate partner violence, sexual abuse or other kinds of violence, and as a result the measures were not standardized accordingly. However, given the large prevalence of these factors, those findings indicate a pressing need for studies to support targeted interventions for Brazilian MSM.

\section{Conclusions}

Most MSM included in the present study were not aware of their partner's HIV serostatus. The high prevalence of UAI with HIV negative or with unknown HIV status male partners indicates that additional prevention strategies are urgently needed for this population. The factors associated with UAI in our study included a lifetime history of violence or sexual abuse, commercial sex and the number of male sexual partners in the past 12 months. The clustering of different health, behavioral, and social problems among these MSM reinforces the need for a comprehensive approach towards treatment and prevention of HIV in this population.

\section{Competing interests}

The authors declare that they have no competing interests.

\section{Authors' contributions}

CBC participated in the design of the study, performed the statistical analysis and wrote the first draft of the manuscript. All authors contributed to the design of the study, writing and revising the manuscript and all authors approved the final version.

\section{Acknowledgements}

RBDB and BG would like to thank the National Council of Technological and Scientific Development -CNPq. BG also thanks the Research Funding Agency of the State of Rio de Janeiro - FAPERJ. The funding sources have no role in study design, analysis and interpretation of data, writing of the manuscript or in the decision to submit the manuscript for publication.

Received: 3 December 2013 Accepted: 10 April 2014

Published: 17 April 2014

\section{References}

1. Beyrer C, Baral SD, van Griensven F, Goodreau SM, Chariyalertsak S, Wirtz AL, Brookmeyer R, Van Griensven F: Series HIV in men who have sex with men 1 Global epidemiology of HIV infection in men who have sex with men. Lancet 2012, 380:367-377.

2. Ministério da Saude Brasil: Boletim Epidemiologico de AIDS/DST. Brasilia: Ministério da Saúde/ Secretaria de Vigilância em Saúde/Departamento de DST, AIDS e Hepatites Virais; 2012.

3. Kerr LRFS, Mota RS, Kendall C, Pinho ADA, Mello MB, Guimarães MDC, Dourado I, De Brito AM, Benzaken A, McFarland W, Rutherford G: HIV among MSM in a large middle-income country. AIDS 2013, 27:427-435

4. Jin F, Crawford J, Prestage GP, Zablotska I, Imrie J, Kippax SC, Kaldor JM, Grulich AE: Unprotected anal intercourse, risk reduction behaviours, and subsequent HIV infection in a cohort of homosexual men. AIDS 2009, 23:243-252.

5. Moatti J, Prudhomme J, Coulibaly D, Juillet-amari A, Akribi HA, Msellati P. Access to antiretroviral treatment and sexual behaviours of HIV-infected patients aware of their serostatus in Côte $d^{\prime}$ Ivoire and the Côte $d^{\prime}$ Ivoire Drug Access Initiative Socio-Behavioural Evaluation Group. AIDS 2003, 33:69-77.

6. Di Pietro N: No turning back: HIV and gay male sexuality. AIDS Community Res Initiat Am Update 2006, 15:12-16.

7. Bauermeister J, Carballo-Dieguez A, Ventuneac A, Dolezal C: Assessing motivations to engage in intentational condomless anal intercourse in HIV-risk contexts ("bareback sex") among men who have sex with men. AIDS Educ Prev 2009, 21:156-168.

8. Seng R, Rolland M, Beck-Wirth G, Souala F, Deveau C, Delfraissy J-F, Goujard C, Meyer L: Trends in unsafe sex and influence of viral load among patients followed since primary HIV infection, 2000-2009. AIDS 2011, 25:977-88. 
9. Jansen IAV, Geskus RB, Davidovich U, Jurriaans S, Coutinho RA, Prins M, Stolte IG: Ongoing HIV-1 transmission among men who have sex with men in Amsterdam: a 25-year prospective cohort study. AIDS 2011, 25:493-501.

10. George C, Alary M, Otis J, Demers E, Remis RS, Mâsse B, Lavoie R, Vincelette J, Parent R, Leclerc R, Turmel B: Nonnegligible increasing temporal trends in unprotected anal intercourse among men who have sexual relations with other men in montreal. J Acquir Immune Defic Syndr 2006, 42:207-12.

11. McFarland W, Chen S, Weide D, Kohn R, Klausner J: Gay Asian men in San Francisco follow the international trend: increases in rates of unprotected anal intercourse and sexually transmitted diseases, 1999-2002. AIDS Educ Prev 2004, 16:13-8.

12. Crepaz N, Marks G, Liau A, Mullins MM, Aupont LW, Marshall KJ, Jacobs ED, Wolitski RJ: Prevalence of unprotected anal intercourse among HIV-diagnosed MSM in the United States: a meta-analysis. AIDS 2009, 23:1617-29.

13. Kippax S, Noble J, Prestage G, Crawford JM, Campbell D, Baxter D, Cooper D: Sexual negotiation in the AIDS era: negotiated safety revisited. AIDS 1997, 11:191-7.

14. Parsons JT, Schrimshaw EW, Wolitski RJ, Halkitis PN, Purcell DW, Hoff CC, Gómez C a: Sexual harm reduction practices of HIV-seropositive gay and bisexual men: serosorting, strategic positioning, and withdrawal before ejaculation. AIDS 2005, 19(Suppl 1):S13-25.

15. Xia Q, Molitor F, Osmond DH, Tholandi M, Pollack LM, Ruiz JD, Catania JA: Knowledge of sexual partner's HIV serostatus and serosorting practices in a California population-based sample of men who have sex with men. AIDS 2006, 20(April):2081-2089.

16. Frost DM, Stirratt MJ, Ouellette SC: Understanding why gay men seek HIV-seroconcordant partners: intimacy and risk reduction motivations. Cult Health Sex 2008, 10:513-27.

17. Rocha GM, Kerr LRFS, de Brito AM, Dourado I, Guimarães MDC: Unprotected receptive anal intercourse among men who have sex with men in Brazil. AIDS Behav 2013, 17(4):1288-95.

18. Rosenberg ES, Sullivan PS, Dinenno EA, Salazar LF, Sanchez TH: Number of casual male sexual partners and associated factors among men who have sex with men: Results from the National HIV Behavioral Surveillance system. BMC Public Health 2011, 11:189.

19. Zekan S, Novotny TE, Begovac J: Unsafe sexual behavior among HIV-infected patients in Croatia, 2006: prevalence and associated factors. AIDS Behav 2008, 12(4 Suppl):S86-92

20. Golin C, Marks G, Wright J, Gerkovich M, Tien H-C, Patel SN, Gardner L, O'Daniels C, Wilson TE, Thrun M, Thompson M, Raffanti S, Quinlivan EB: Psychosocial characteristics and sexual behaviors of people in care for HIV infection: an examination of men who have sex with men, heterosexual men and women. AIDS Behav 2009, 13:1129-42.

21. Mimiaga M, Noonan E, Donnel D, Safren A, Koenen KC, Gortmaker S, Cleirigh CO, Mayer K: Childhood sexual abuse is highly associated with HIV-risk taking behavior and infection amomg MSM in the EXPLORE study. J Acquir Immune Defic Syndr 2012, 51:340-348.

22. Pantalone DW, Rood BA, Morris BW, Simoni JM: A systematic review of the frequency and correlates of partner abuse in HIV-infected women and men who partner with men. J Assoc Nurses AIDS Care 2014, 25(1 Suppl):S15-35.

23. Koblin BA, Husnik MJ, Colfax G, Huang Y, Madison M, Mayer K, Barresi PJ, Thomas J, Chesney MA, Buchbinder S: Risk factors for HIV infection among men who have sex with men. AIDS 2006, 20(September 2005):731-39.

24. Bajunirwe F, Bangsberg DR, Sethi AK: Alcohol use and HIV serostatus of partner predict high-risk sexual behavior among patients receiving antiretroviral therapy in South Western Uganda. BMC Public Health 2013, 13:430

25. Carey JW, Mejia R, Bingham T, Ciesielski C, Gelaude D, Herbst JH, Sinunu M, Sey E, Prachand N, Jenkins RA, Stall R: Drug use, high-risk sex behaviors, and increased risk for recent HIV infection among men who have sex with men in Chicago and Los Angeles. AIDS Behav 2009, 13:1084-96.

26. Deiss RG, Clark JL, Konda KA, Leon SR, Klausner JD, Caceres CF, Coates TJ: Problem Drinking is Associated With Increased Prevalence of Sexual Risk Behaviors Among men who Have sex With men (MSM) in Lima. Drug Alcohol Depend: Peru; 2013

27. Vosburgh HW, Mansergh G, Sullivan PS, Purcell DW: A review of the literature on event-level substance use and sexual risk behavior among men who have sex with men. AIDS Behav 2012, 16:1394-410.

28. Cohen MS, Chen YQ, McCauley M, Gamble T, Hosseinipour MC, Kumarasamy N, Hakim JG, Kumweda J, Grinsztejn B, Pilotto JH, Godbole SV,
Mehendale S, Chariyalertsak S, Santos BR, Mayer KH, Hoffman IF, Eshleman SH, Piwowar-Manning E, Wang L, Makhema J, Mills LA, De Bruyn G, Sanne I, Eron J, Gallant J, Havlir D, Swindells S, Ribaudo H, Elharrar V, Burns D, et al: Prevention of HIV-1 infection with early antiretroviral therapy. N Engl J Med 2011, 365(6):493-505.

29. Van de Ven P, Mao L, Fogarty A, Rawstorne P, Crawford J, Prestage G, Grulich A, Kaldor J, Kippax S: Undetectable viral load is associated with sexual risk taking in HIV serodiscordant gay couples in Sydney. AIDS 2005, 19:179-84.

30. Bruce D, Kahana S, Harper GW, Fernández MI, The Atn: Alcohol use predicts sexual risk behavior with HIV-negative or partners of unknown status among young HIV-positive men who have sex with men. AIDS Care 2013, 25:559-65.

31. Mayer K, Wang L, Hoffman I, McCauley A, Li X, Safren S, Gamble T, Talley J, Cottle L, Piwowar-Manning E, Akelo V, Badal-Faesen S, Chotirosniramit N, Fernandes N, Kumarasamy N, Shay S, Makhema J, Panchia B, Pilotto J, Santos B, Cohen M, IAS: Sustained Treatment as Prevention: Continued Decreases in Unprotected sex and Increases in Virological Suppression After HAART Initiation Among Participants in HPTN 052. In XIX International AIDSConference. Washington, D.C: 2012. Available at http://www.hptn.org/ web\%20documents/hptn052/AIDS2012/052MayerMOPDC0106.pdf.

32. Crepaz N, Hart TA, Marks G: Highly active antiretroviral therapy and sexual risk behavior: a meta-analytic review. JAMA 2004, 292:224-36.

33. Phillips AN, Cambiano V, Nakagawa F, Brown AE, Lampe F, Rodger A, Miners A, Elford J, Hart G, Johnson AM, Lundgren J, Delpech VC: Increased HIV incidence in men who have sex with men despite high levels of ART-induced viral suppression: analysis of an extensively documented epidemic. PLoS One 2013, 8:e55312.

34. Elford J: Changing patterns of sexual behaviour in the era of highly active antiretroviral therapy. Curr Opin Infect Dis 2006, 19:26-32.

35. McCullagh P, Nelder J: Generalized Linear Models. 2nd edition. London: Chapman \& Hall; 1989.

36. Harrell FEJ, Lee KL, Pollock BG: Regression models in clinical studies: determining relationships between predictors and response. J Natl Cancer Inst 1988, 80:1198-202.

37. Ackers M-L, Greenberg AE, Lin CY, Bartholow BN, Goodman AH, Longhi M, Gurwith M: High and persistent HIV seroincidence in men who have sex with men across 47 U.S. cities. PLoS One 2012, 7:e34972.

38. Greenland S: Modeling and variable selection in epidemiologic analysis. Am J Public Heal 1989, 79:240-9.

39. Hosmer DW, Hosmer T, Lemeshow S, le Cessie S: A comparison of goodness-offit tests for the logistic regression model. Stat Med 1997, 16:965-80.

40. R Foundation for Statistical Computing: R. 2013. http://www.r-project.org/.

41. Nagaraj S, Segura ER, Peinado J, Konda KA, Segura P, Casapia M, Ortiz A Montano SM, Clark JL, Sanchez J, Lama JR: A cross-sectional study of knowledge of sex partner serostatus among high-risk Peruvian men who have sex with men and transgender women: implications for HIV prevention. BMC Public Health 2013, 13:181

42. De Boni RB, Veloso V, Grinsztejn B: The epidemiology of HIV in Latin America and the Caribbean. Curr Opin HIV AIDS 2014, 9(2):192-8.

43. Grant RM, Lama JR, Anderson PL, McMahan V, Liu AY, Vargas L, Goicochea P, Casapía M, Guanira-Carranza JV, Ramirez-Cardich ME, Montoya-Herrera O, Fernández T, Veloso VG, Buchbinder SP, Chariyalertsak S, Schechter M, Bekker L-G, Mayer KH, Kallás EG, Amico KR, Mulligan K, Bushman LR, Hance RJ, Ganoza C, Defechereux P, Postle B, Wang F, McConnell JJ, Zheng J-H, Lee J, et al: Preexposure chemoprophylaxis for HIV prevention in men who have sex with men. N Engl J Med 2010, 363:2587-99.

44. Gomez GB, Borquez A, Caceres CF, Segura ER, Grant RM, Garnett GP, Hallett TB: The potential impact of pre-exposure prophylaxis for HIV prevention among men who have sex with men and transwomen in Lima, Peru: a mathematical modelling study. PLoS Med 2012, 9:e1001323.

45. Schackman BR, Eggman AA: Cost-effectiveness of pre-exposure prophylaxis for HIV: a review. Curr Opin HIV AIDS 2012, 7:587-92.

46. Houston E, McKirnan DJ: Intimate partner abuse among gay and bisexual men: risk correlates and health outcomes. J Urban Health 2007, 84:681-90.

47. Finneran C, Chard A, Sineath C, Sullivan P, Stephenson R: Intimate partner violence and social pressure among gay men in six countries. West $J$ Emerg Med 2012, 13:260-71.

48. Finneran C, Stephenson R: Intimate partner violence among men who have sex with men: a systematic review. Trauma Violence Abuse 2013, $14: 168-85$. 
49. Siddiqui AUR, Qian H-Z, Altaf A, Cassell H, Shah SA, Vermund SH: Condom use during commercial sex among clients of Hijra sex workers in Karachi, Pakistan (cross-sectional study). BMJ Open 2011, 1:e000154.

50. Brahmam GNV, Kodavalla V, Rajkumar H, Rachakulla HK, Kallam S, Myakala SP, Paranjape RS, Gupte MD, Ramakrishnan L, Kohli A, Ramesh BM: Sexual practices, HIV and sexually transmitted infections among self-identified men who have sex with men in four high HIV prevalence states of India. AIDS 2008, 22(Suppl 5):S45-57.

51. Chow EPF, lu KI, Fu X, Wilson DP, Zhang L: HIV and sexually transmissible infections among money boys in China: a data synthesis and meta-analysis. PLoS One 2012, 7:e48025.

52. Zhang L, Zhang D, Yu B, Wang S, Liu Y, Wang J, Li X, Shang X, Li H: Prevalence of HIV infection and associated risk factors among men who have sex with men (MSM) in Harbin, P. R. China. PLoS One 2013, 8:e58440.

53. McDaid LM, Hart GJ: Serosorting and strategic positioning during unprotected anal intercourse: are risk reduction strategies being employed by gay and bisexual men in Scotland? Sex Transm Dis 2012, 39:735-8.

54. Clark J, Salvatierra J, Segura E, Salazar X, Konda K, Perez-Brumer A, Hall E, Klausner J, Caceres C, Coates T: Moderno love: sexual role-based identities and HIV/STI prevention among men who have sex with men in Lima, Peru. AIDS Behav 2013, 17:1313-28.

55. Durham MD, Buchacz K, Richardson J, Yang D, Wood K, Yangco B, Brooks JT: Sexual risk behavior and viremia among men who have sex with men in the HIV Outpatient Study (HOPS), USA, 2007-2010. J Acquir Immune Defic Syndr 2013, 63:372-78.

56. Stoner SA, George WH, Peters LM, Norris J: Liquid courage: alcohol fosters risky sexual decision-making in individuals with sexual fears. AIDS Behav 2007, 11:227-37.

57. Fritz K, Morojele N, Kalichman S: Alcohol: the forgotten drug in HIV/AIDS. Lancet 2010, 376:398-400.

58. Sander PM, Cole SR, Stall RD, Jacobson LP, Eron JJ, Napravnik S, Gaynes BN, Johnson-Hill LM, Bolan RK, Ostrow DG: Joint effects of alcohol consumption and high-risk sexual behavior on HIV seroconversion among men who have sex with men. AIDS 2013, 27:815-23.

59. Singer M, Clair S: Syndemics and public health: reconceptualizing disease in bio-social context. Med Anthropol Q 2003, 17:423-41.

60. Wagner G, Brondolo E, Rabkin J: Internalized homophobia in a sample of HIV + gay men, and its relationship to psychological distress, coping, and illness progression. J Homosex 1996, 32:91-106.

61. Ross MW, Kajubi P, Mandel JS, McFarland W, Raymond HF: Internalized homonegativity/homophobia is associated with HIV-risk behaviours among Ugandan gay and bisexual men. Int J STD AIDS 2013, 24:409-13.

62. Williamson IR: Internalized homophobia and health issues affecting lesbians and gay men. Health Educ Res 2000, 15:97-107.

63. Newcomb ME, Mustanski B: Moderators of the relationship between internalized homophobia and risky sexual behavior in men who have sex with men: a meta-analysis. Arch Sex Behav 2011, 40:189-99.

doi:10.1186/1471-2458-14-379

Cite this article as: Cunha et al:: Unprotected sex among men who have sex with men living with HIV in Brazil: a cross-sectional study in Rio de Janeiro. BMC Public Health 2014 14:379.

\section{Submit your next manuscript to BioMed Central and take full advantage of:}

- Convenient online submission

- Thorough peer review

- No space constraints or color figure charges

- Immediate publication on acceptance

- Inclusion in PubMed, CAS, Scopus and Google Scholar

- Research which is freely available for redistribution 